\title{
SEX OFFENSES: THE MARGINAL STATUS OF THE ADOLESCENT*
}

\author{
Albert J. Reiss $\dagger$ \\ INTRODUCTION
}

Adolescence is not a highly institutionalized position in American society. ${ }^{1}$ It is a transitional status between childhood and adulthood, but it is less institutionalized than either of the two age-based status positions that it borders and connects. The adolescent is a marginal person who is no longer accorded the privileged status of the child, nor as yet many of the rights and responsibilities of the adult.

The relatively low degree of institutionalization of adolescence as a status position and the marginal position of the adolescent in terms of role expectations in American society are reflected in the fact that most of the norms governing adolescent behavior do not have adolescent behavior patterns as their reference point. Rather, the norms and expectations governing adolescent behavior have either child or adult behavior patterns as their reference point. The exhortations of parents and other adults admonish the adolescent either to "behave like a grown-up" or to "quit behaving like a child." They rarely encourage him to "behave like an adolescent." There are, then, no highly institutionalized expectations of how one is to behave like an adolescent, in the sense that achievement of these status expectations is a positive transitional link with the adult status.

This article is an attempt to show that the failure to accord adolescence a distinct status position that is closely integrated with the larger structure of American society and the resulting minimum institutionalization of norms for governing adolescent behavior has several very important implications for defining and sanctioning the sexual conduct of adolescents in our society:

I. The perception of adolescent sex offenders as neither children nor adults tends to (a) encourage considerable variation in definition of their sexual offenses; (b) lead to preferential treatment and differential adjudication of their cases of sexual behavior on the basis of age, sex, socioeconomic status, and jurisdictional

- The writer gratefully acknowledges his obligation to Clark E. Vincent for helpful comment and criticism.

†Ph.B. 1944, Marquette University; M.A. 1948, Ph.D. I949, University of Chicago. Professor of Sociology and Chairman, Department of Sociology and Anthropology, State University of Iowa. Author, [with Paul K. Hatt] Reader in URBan Sociology (I95I), [with Otis Dudley Duncan] Social Characteristics of Urban and RuRal Communities, 1950 (1956), [with Elizabeth Wirth Marvick] Community Life and Social Policy: Selected Papers by Louis Wirth (i956), Ciries and Societies (1957), [with A. Lewis Rhodes] A Socro-Psychological Study of Adolescent Conformity and Deviation (1959). Contributor to scholarly publications.

1 Throughout this article, the sociological concept of adolescent is used interchangeably with the legal concept of juvenile. The context should make clear whether the concept is used primarily in the specialized sense of one discipline or the other. 
considerations; and (c) obscure the degree to which they are denied the due process of law.

2. The age-based status reference point for evaluating adolescent sexual offenses is a factor in the sanctions applied to their deviation. When adolescent sex offenders are viewed as "not adult," they are generally overprotected and absolved from moral responsibility for their behavior, thereby weakening the moral integration of the total society. When they are viewed as "not children," there often is a tendency to deal more punitively with them than with adults who commit similar sex offenses.

3. The sexual behavior of adolescents is primarily peer-organized and peer-controlled. As such, it reflects the attempt by adolescents to achieve a compromise between being encouraged to behave like adults and being denied the rights and privileges of that status. An examination of the peer-organized basis for adolescent sexual conduct provides a normative basis for evaluating their behavior in relation to the larger social structure in which they are held accountable for their behavior.

\section{The Effect of Adolescent Status on Dealing With Sexuad Conduct}

What acts committed by adolescents will be defined as violations of sexual conduct norms? And how will his status as "not child" and "not adult" encourage variability in the definition of an adolescent's sexual conduct as a sex offense?

Despite some variation in the legal codes from state to state in our society, the statutes define the acts for which violators are classified as adult sex offenders. But the problem is not as simple for defining the juvenile as a sex offender. Most juvenile court statutes not only define the violation of all criminal statutory codes as sufficient ground for a finding of delinquency, but also hold that if the child is growing up in a situation inimical to his welfare, he or she may be adjudicated a delinquent. For all practical purposes, then, the definition of a juvenile sex offender rests with the standards followed in each juvenile jurisdiction. ${ }^{2}$ The statutes, in fact, prescribe that the finding be that the child is a delinquent person, and not a specific type of offender.

Going beyond the immediate jurisdiction of the court to the legal institutions for the care and treatment of juvenile offenders, one finds that still other standards may be applied in defining what is a sex offense. Reaching out into the social environment of juveniles, one quickly finds further variation in what is a sex offense, depending upon the status environment of the juvenile's family, his adolescent peers, and the

- Appeal from the decisions rendered by a juvenile court are relatively rare, and particularly so for cases involving violations of sexual conduct norms. The relatively low rate of appeal from the decisions of a juvenile court itself reflects a social definition of the adolescent as a person whose best interest is protected by the court, so that the traditional safeguards for civil rights are unnecessary. This position needs careful examination, since many juveniles and their families are unaware of their legal rights in a juvenile hearing. The personnel in most juvenile jurisdictions make no attempt to apprise juveniles of their rights and, in fact, often express obvious resentment when the juvenile is represented by counsel. 
institutional organizations within the community. There is no question but that in any of these contexts-the family, peer group and community, including the organizations administering justice-all forms of sex activity, including nocturnal emissions, may be prima facie evidence of the violation of sexual norms, so that negative sanctions may be invoked against the person engaging in the behavior.

The governing statutes are phrased in such general and inclusive terms that any sexual act or conduct can be defined as a delinquent offense. The omnibus provision for "immoral conduct or behavior" can be construed to cover all deviations from sexual conduct norms. The body of legal opinion and decision for delinquent acts similarly reflects considerable ambiguity as to what sexual conduct is to be defined as a violation and what is permitted sexual behavior for adolescents. Juveniles who are held to be guilty of a sex offense often are not charged with a specific sex conduct violation. The categories of "ungovernability," "loitering," "immoral or indecent conduct," "runaway," and similar designations frequently are the preferred charges, particularly if the court has a policy to avoid stigmatizing an individual with a sex offense. The terms "sex offense" and "sex offender" are not clearly defined, then, for adolescents in legal codes or in the adjudication of cases involving the violation of sexual conduct norms.

Most forms of behavioral deviation from norms or legal codes are linked with other forms of behavioral deviation, at least for a substantial proportion of all known deviators. For this reason, a person classified as a violator of legal or other conduct norms governing sexual behavior also may usually be classified as violator of other legal conduct norms. An adolescent boy or girl who is arrested for stealing almost alway's has also violated sexual conduct norms, and the reverse is usually the case as well. In behavioral terms, then, it is not particularly meaningful to define a person as a sex offender. This, of course, is true of most other delinquency classificatory terms as well. One technically violates the sexual conduct norm through behavior and thereby commits a delinquent offense. The term sex offender should perhaps signify no more nor less than this. Certainly, it should not imply that this is the only major kind of delinquent activity the person has committed. To classify a person as a sex offender may only serve to develop self and public definitions of the person as a sex offender.

The term sex offender, of course, is very ambiguous since it does not specify the specific kind of behavior that is used as the basis for charging a violation. But even if one employs specific behavioral definitions-as, for example, by designating the person as an exhibitionist or an unwed mother-the charge usually would not exhaust the sexual conduct violations for which the person could be charged. As Kinsey and others have shown, total sexual outlet is derived from a variety of types of sexual behavior, ${ }^{3}$ almost any one of which could in the case of many adolescents be used to

${ }^{3}$ Alfred C. Kinsey, Wardeli B. Pomeroy \& Clyde E. Martin, Sexual Behavior in the Human Male passin ( 1948 ) [hereinafter cited as Kinsey Male Report]; Alfred C. Kinsey, Wardelt B. Pomeroy, Clyde E. Martin \& Paul H. Gebhard, Sexual Behavior in the Human Female passim (1953) [hereinafter cited as Kinsey Female RePort]. 
charge conduct violation. Although there is difficulty in classifying a person as a type of offender when an act of sexual behavior violates a conduct norm, the simple cumulation of such acts as a basis for classifying a person as a specific type of offender (e.g., persistence) involves one in even greater difficulty. Not only is it difficult to secure accurate and reliable statistics on violation of sexual conduct norms for adolescents charged with a sex offense, but, as Kinsey observes, the frequency distribution is continuous for any kind of sexual behavior; any cutting point chosen on that curve, therefore, is arbitrary. ${ }^{4}$

The status of adolescent is an apparent factor in the application of adult sex norms to their conduct. The prescribed form of sexual behavior in American society is that of heterosexual coition in private surroundings between partners in a monogamous marriage. The legal norms, however, specifically prohibit adolescents to marry without the consent of parents. Unless this condition is met, therefore, heterosexual coition is proscribed for an adolescent. This example is instructive in that the norms do not specifically prohibit young persons from engaging in heterosexual coition; the limitation rather arises for adolescents because of difficulty in satisfying the conditions for marriage. Adolescents lack both the privilege and opportunities for self-determination of their marital status and thereby for their heterosexual behavior that culminates in sexual intercourse. It is not surprising, therefore, that for adolescents, petting to orgasm becomes a functional equivalent to coition.

Adolescents themselves set standards for what is a violation of their sexual codes. The standards in these adolescent codes vary considerably according to the social status position of the adolescent and his family in the larger society. A comparison of the prescribed heterosexual coition patterns of middle- and lower-status boys and girls may illustrate this variability. Among the lower-status white adolescent boys in our society, premarital heterosexual intercourse is prescribed to secure status within the group, while it is not necessary to secure status within most middle-peer status groups, even though it does confer some status.

Heterosexual behavior with prostitutes is not very common among adolescents up to the age of fifteen, although it is more common after that age. For adolescent boys, however, intercourse with female prostitutes comprises only a relatively small proportion of their total sexual outlet. Premarital sexual intercourse apart from organized prostitution is far more common among boys than is intercourse with prostitutes.

Among young lower-status adolescent boys, perhaps the most common mode of heterosexual intercourse is the "gang-shag" or "gang-bang." A gang of boys usually knows one or more girls who are easy "pick-ups" for the group who will consent to serial intercourse with the members of the gang. To understand this behavior, several peer normative factors need to be taken into account. First of all, the girl in the "gang-bang" almost always is one who gives her consent. She is not being sexually exploited in any sense of forcible rape. In fact, when she consents to being

\footnotetext{
- Kinsey Mate Report r9g.
} 
picked up, she understands that she is to be a partner in heterosexual coition. Lowerstatus boys clearly distinguish between "putting it to a girl" (she consents) and "making a girl" (she does not consent). Few lower-status boys, particularly delinquent boys, will "make a girl," although almost all frequently engage in heterosexual intercourse and most have at least participated in a gang-bang. Most lowerstatus adolescent boys express the view: "Why should I make a girl when I can get all I want without it." The opportunities for heterosexual coition with consent are ever present to lower-status boys, so that they negatively sanction forcible rape. This is not to say that some adolescent girls are not forcibly raped by an adolescent boy or even a gang, but the proportion who are is, without doubt, very small.

The girl who consents to sexual intercourse with the gang loses her reputation as a "nice girl," and they no longer regard her as a possible partner in a marriage relationship. 5 Her status becomes that of a prostitute. Similarly, a girl who consents to sexual intercourse with a number of boys, even if the acts are separate and private, risks her reputation as a partner in marriage. The status of an "easy mark" in sexual intercourse sharply reduces her life chances for marriage, at least among the lower-status boys who are acquainted with her. As a consequence, sexual behavior becomes her only competitive claim to masculine attention. This very loss of status as "marriageable," with the substitute status as "easy-to-get," gradually forces the girl either to withdraw altogether from the competitive struggle for the attentions of boys or to bargain increasingly the only thing she has-i.e., sexual favors. ${ }^{6}$

The adolescent girl faced with the status dilemma described above is likely to adopt one of two solutions to the problem. One of these is the "steady date," which includes the "understanding" that he has sexual access to her and she is guaranteed a steady date-she does not have to compete with other girls for a date. Under these circumstances, the girl can defend her behavior in terms of romantic love ideals. Many middle- and upper-status girls undertake heterosexual coitus under these circumstances, since it protects their status within the group. They are "in love," "going steady," and "intend to be married"; ergo, if coition is a private act between two who are as married, it can be permitted. The other major alternative is some form of prostitution, either in organized prostitution or through the acquisition of a status or reputation as a "pick-up" or "easy-to-get" girl. The major risk a girl encounters in either solution is that of pregnancy, while in the case of prostitution, she also runs a fairly high risk of venereal infection.

It is not so much the sexual act of coition that brings the girl to the attention of legal authorities as it is either of these consequences of the act-premarital pregnancy or venereal infection. The couple is seldom caught in the act of coition. Since girls are more likely than boys to be defined as the carriers of venereal infection, a girl who

\footnotetext{
'See, e.g., Whyte, A Slum Sex Code, 49 AM. J. Socrologr 24 (1943). Investigation since Whyte's original statement of this sex code discloses that this might more appropriately be called the sex code of low-status persons in American society, whether or not they dwell in slums.

${ }^{\circ}$ Sec James F. Coleman, Social Structures and Social Climates in High Schools chs. 3 and 4 (1959).
} 
is picked up by police or juvenile authorities is almost always given a physical examination to determine whether she has had sexual intercourse, now has a venereal infection, or is pregnant. This is particularly true for runaway girls. Boys seldom are given as complete a physical examination for venereal infection as are girls. Even less often are they questioned as to their sex experiences. There is a great variation among jurisdictions in this respect, however. Personnel in some are more likely than in others to learn about the sexual deviation of girls. The life chances of a girl before police and juvenile authorities, therefore, are more favorable to definition as a sex delinquent than are the life chances of the boy.

A number of other factors are important in the greater relative frequency with which girls, as compared with boys, are defined as sex offenders. Many policemen come from lower-status social origins. In their youth, many of them, therefore, shared the sex patterns of the lower-status boys and accepted the norm that deviation in heterosexual intercourse is permissible. So long as the boys do not forcibly rape a girl, or so long as the girl's parents or others do not file a complaint, the police are generally accepting of this form of sexual deviation. They may make a concerted effort to limit the opportunities for deviation, since that is expected of them in their work role, but they seldom arrest on discovery. Discovery in the act of intercourse is difficult, so that evidence is almost always obtained by confession or circumstances.

Adolescent boys come to the attention of the court as heterosexual sex offenders usually only when the morality of the girl's family is offended. The most common form of complaint is for the family to define coition as "rape" of their daughter. Research evidence shows that in most cases, the boy is not a rapist in any technical sense that force or coercion was used. The act occurred through common consent. The complaint arises because the girl, under family pressure, charges that she did not consent. Although many complaints arise in this way, it does not follow, of course, that some delinquent boys gangs do not forcibly rape a young girl nor that boys individually do not engage in such acts; it is rather to emphasize that available evidence strongly indicates that most heterosexual coition between adolescents occurs through mutual consent. The girl has a reputation. She is sought out or picked up. She knows what is expected of her, consents, and services one or more boys. No money is exchanged.

Middle-status boys do not prescribe premarital intercourse, and certainly not at as early an age as do lower-status boys. Experience in heterosexual coition confers status, however. The middle-status white adolescent boy assumes no obligation for premarital pregnancy, and marriage under these circumstances is to be avoided. The preservation of a middle-status boy's reputation is more important than the preservation of the reputation of the girl, particularly if she is of lower social status. Community organizations will strive to preserve his reputation, even at the expense of the reputation of the girl.

It has been suggested that a major difference between lower- and middle-status adolescents in respect to premarital intercourse is that lower-status girls commonly 
enter into the relationship by perceiving it as fun morality- "if it's fun, it's good"while middle-status girls see it as one involving love morality- "it's good because we're in love."

Status within a peer group is a very important factor determining whether an adolescent girl will engage in coition with boys. Courtship patterns in American society require that girls use a variety of means to attract males as dates or potential marriage partners when in competition with other girls for these boys. One of the competitive advantages a girl has available to her is her sexual attractiveness to. males. Yet, the male norms prescribing the ideal marriage mate require that the girl one marries cannot have a reputation among other males as being sexually immoral. A girl's competitive advantage, therefore, is easily lost if she gains the reputation that she will enter into a sexual liaison with a boy if she is dated. Recent research shows that the adolescent girl who fails to acquire status within a conforming adolescent peer group of girls is at a competitive disadvantage in securing dates with boys, since dating is largely controlled by peer groups of boys and of girls who enter into "diplomatic relations" with one another. The failure to acquire status within a peer group of girls forces a girl to date by herself rather than "double date," to use more overt means of sexual attractiveness to get a date, or to withdraw from dating competition altogether. The use of any means to get dates other than those controlled by the peer group of girls results in her further exclusion from the peer society and leads to a definition of her as "sexually loose." Girls often communicate such definitions to groups of boys before the boys have formed a similar evaluation of the girl. An adolescent girl's status as being sexually immoral, therefore, often arises among girls rather than among boys. ${ }^{8}$ Having acquired such an unfavorable definition then further deprives a girl of using conventional dating attributes as a means for getting the attention of boys in competition with other girls. Gradually, her only means for getting a date, therefore, is her reputation of ease of sexual acecss. She progressively is forced to resort to the use of this means if she hopes to attract boys as dates, and her behavior must conform to the boy's expectations once she gets the date.

The single most important reason, perhaps, why most adolescents who engage in premarital coition are not defined as delinquents is the difficulty in detectingcouples in the act of violation and obtaining evidence of coition. For the most part, adolescent violators have a strong social status investment in not being discovered. This renders detection even more difficult. Violators, therefore, seldom come to the attention of the police or juvenile officials unless a girl involved in heterosexual coition, or her family, enters a formal complaint. Interrogation then is the principal means for determining whether the accused boy or boys are guilty of the offense. In some jurisdictions, even a lie-detector then is used on the boy, without any regard

\footnotetext{
${ }^{7}$ Vincent, Ego Involvement in Sexual Relations: Implications for Research on Illegitimacy, 65 AM. J. Sociology 287 (1959).

${ }^{8}$ See Colman, op. cit. supra note 6, chs. 3 and 4 .
} 
for his consent, in an effort to determine whether or not the behavior was as charged. Middle-status families generally will not risk the reputation of their daughter by bringing heterosexual violations to the attention of the police and courts, while lower-status families are less likely to see such a risk for their daughter. The lowerstatus family, in fact, sometimes sees formal complaint as necessary to protect the status reputation of their daughter. The effect of these status differences in the discovery and reporting of sexual violations is that the lower-status boy or girl is more likely to come to the attention of the police and courts as a sex violator than is the middle-status adolescent.

One is impressed with the fact that the judge and personnel attached to juvenile courts produce considerable variation in defining what is to be regarded as a sexual offense and who is to be classified as a sex offender. Some years ago, the writer observed delinquency petition hearings before a metropolitan juvenile court and examined the records for some 1500 cases of the court adjudicated by a single judge. During this time, the judge refused to treat any form of sexual behavior on the part of boys, even the most bizarre forms, as warranting more than probationary status. The judge, however, regarded girls as the "cause" of sexual deviation of boys in all cases of coition involving an adolescent couple and refused to hear the complaints of the girl and her family; the girl was regarded as a prostitute. Observation within a southern county jurisdiction some years later, where a religious fundamentalist judge presided, showed almost the opposite pattern in decisions. The girl was invariably seen as victimized by the boy.

Much of the variability in juvenile court jurisdictional standards as to what is a sex offense and who is a sex offender is attributed to differences among court personnel, including the presiding judge. The question can be raised, however, as to why such variability is possible. What is it within the juvenile court structure that permits such variability in standards and practices? The answer can largely be found within the structure of the juvenile court itself and the definition of delinquency in the statutes.

Juvenile courts were founded largely on two principles: The individual rights of the delinquent child were to be safeguarded by the court acting in the role of parens patriae, and the minor was to be protected from the association with adult criminals and from the application of rules of law for adult criminals that were deemed inapplicable to minors in many instances. The putative advantage of the court was that it would prevent juveniles from moving into a life of adult crime.

This is not the place to examine in detail whether the juvenile court has operated within these principles. It seems clear, however, that most juvenile court jurisdictions do not operate to safeguard the rights of minors in terms of the due process of law, that facts in juvenile court proceedings are subject to considerable interpretation and opinion, and that the probability of appeal from decisions of juvenile court decisions is, for many reasons, quite low. The result is that individual prejudice and opinion on the part of arresting officials and of court personnel are particularly likely to play 
an important role in adjudication of juvenile court cases. The word of police officers and of court investigators and the opinion of judges largely go unchallenged, particularly if the juvenile is from a low-status family. The juvenile may even be forced to take a lie-detector test without his consent, and almost any kind of evidence is admissible in reaching a decision that he is to be adjudicated as a delinquent.

These violations of civil rights and the disregard for due process arise from the ambiguous status position of the adolescent in American society. The adolescent is held accountable for violations of adult sexual norms, but is not entitled to the rights and privileges of adults before the courts. Put in another way, juveniles are assigned a special legal status where they are "not adult" and "not child," but where punishment or justice is administered for not conforming to adult norms. In general, it might be said that the principles and procedures of juvenile courts need to be carefully examined from the standpoint of assigning definite rights and privileges to the juvenile. These rights should be consistent with an adolescent status position that is integrated into the total structure of society. The assignment of such rights and privileges and the recognition of their importance in adjudicating an individual delinquent seems imperative in a society that is increasingly becoming conscious of problems of civil rights.

The ambiguities of adolescent status and the variation in procedures for adjudging an individual delinquent granted to juvenile court jurisdictions make it possible for prejudice and opinion to enter into decisions about juveniles more than it does in the case of adults. Since interpretations of sexual deviation are particularly fraught with prejudice and opinion in American society, the court is particularly prone to adjudicate cases of sex violation where these factors are operative.

Mention has already been made of the fact that juvenile court statutes permit a wide range of behavior to be defined as delinquent. This is, of course, owing in part to the fact that in a technical sense, juvenile court judges do not enter a finding of guilt for a specific crime. The minor is simply adjudged a delinquent. ${ }^{9}$ This legal technicality, however, obscures the fact that the decision to enter a finding of delinquency is based on a prior finding that behavioral acts violate either criminal codes or provisions of the juvenile court act. Proof of delinquency is a necessary part of adjudication. ${ }^{10}$ The difficulty in adjudicating cases involving sex offenses lies in the fact that there is at least a double standard for adolescent and adult.

Only two states, Indiana and Wyoming, ${ }^{11}$ have ever held it a crime to encourage a person to masturbate, and none makes it a criminal offense for an individual to masturbate. Juvenile court statutes, however, permit masturbation to be defined as immoral conduct, particularly if it occurs in a group setting, as it sometimes does

\footnotetext{
- Most states specifically deny the juvenile court any power of conviction. See, e.g., Mickens v. Commonwealth, 178 Va. $273,278-79$, I6 S.E.2d 641,643 (I94I), where the trial and punishment of juveniles for a specific offense is specifically prohibited.

${ }^{10}$ In the Matter of Arthur Lewis, 260 N.Y. $x 7$, I 83 N.E. 353 (1932).

${ }^{12}$ Ind. ANn. Stat. \$ ro-422I (I956); Wyo. Comp. Stat. Ann. \$ 9-520 (1945).
} 
among adolescent boys. But it is only rarely that the court will adjudicate such cases.

Many Americans, particularly at the lower-social-status levels, still condemn maturbation. Nowhere is this condemnation more apparent than in the codes governing sex behavior in institutions for adolescents. Masturbation is usually severely condemned within these institutions, and punishment is administered for its practice. At one such institution, a state training school for boys, the writer recently discovered that boys were physically punished if caught in the act of masturbation. Repeated violation resulted in confinement to the disciplinary dormitory of the institution. Such administrative policies within institutions to which delinquents are committed by the court or in which delinquents are held in detention by the court appears only to heighten the ingenuity of adolescents to seek more clandestine modes of sexual outlet. Among other consequences, the policy may only serve to exacerbate the problem of controlling homosexual practices in these singlesex institutions.

Homosexual behavior takes many forms and over a period of time involves such a large proportion of persons that it is difficult to treat these behaviors as having very much in common from a sociological or a psychological viewpoint. The laws regarding homosexual behavior appear as statutes against sodomy, crimes against nature, unnatural acts, buggery, indecent behavior, and lewd or lascivious conduct. To avoid the stereotyping of a boy as a "homosexual," some juvenile court jurisdictions, in fact, charge either "indecent behavior," "lewd and lascivious conduct," or "loitering." The penalties prescribed in criminal statutes for homosexual behavior are generally so severe that acts of sexual deviation are not punished as severely in any nation as in the United States. There is a tendency for juvenile court jurisdictions to ignore homosexual behavior among adolescent boys of the same age, so long as common consent is involved. At the same time, there is a countertendency to treat boys involved in homosexual acts as mentally ill. The problem of homosexual behavior among adolescent girls seems almost altogether ignored. There is one instance, however, in which the court may define the problem as a serious one, and that is where the boy or girl is involved in a homosexual relationship with an adult. This type of relationship is particularly common among lower-status boys and adult males. Lowerstatus, career-oriented delinquent boys often are involved in some form of sexual relationship with an adult male.

The sexual mores for single adolescents in American society are ambiguous. If the conditions for the prescribed form of sexual behavior are not met, then abstinence is prescribed. Basically, this norm assigns all other forms of sex behavior to a lower normative order. Not all other forms are tabooed, however, since who does what to whom, how, and under what circumstances will determine public reaction and sanctions to the sexual behavior. There are several basic elements that will determine 
the reaction to the kinds of sexual behavior between persons in different combinations of social positions under varying social circumstances.

The first of these elements is the social visibility of the offense. The more public the circumstances in which any sexual behavior takes place, the stronger the taboo and the sanctions against violators. By way of illustration, masturbation is generally permitted in private, but it is strongly tabooed in public as a form of exhibitionism.

A second element is the social visibility of the offender. The offender may be socially visible apart from the offense. Thus, an unmarried woman whose pregnancy is noticed is known to have transgressed the mores. ${ }^{12}$ The transvestite, by reversing sex roles, is perceived as guilty of a sexual offense, although sexual acts are seldom actually observed for them. In adopting the clothing of the opposite sex, the transvestite invites strong public reaction, since the reversal of social roles becomes socially visible.

An extremely important element determining public reaction to acts of sexual deviation is the degree to which the status and role of the participants in the sexual act depart from the status and role expectations for these persons apart from the sexual act itself. In American culture, the male is expected to assume active roles and the female, passive roles. The degree to which the male departs from the masculine, active sex role or the female departs from the feminine, passive sex role, therefore, is a factor in public reactions to the deviating sexual act. The "pansy" and the "castrating female" both seem more likely to be sanctioned for homosexual deviation than are the participants who fulfill conventional active-passive sex-role expectations. The socialization of children requires that parent-child authority relations be maintained. Incest is universally tabooed primarily because the status and role expectations for family members cannot be fulfilled when heterosexual behavior is permitted between members of the same nuclear family. ${ }^{13}$ Upper- and particularly middle-status persons in American society are regarded as the guardians of morality; women are so regarded more than men. Lower-status persons are regarded as persons to be condemned or saved from their immoral behavior. These norms apply as well to sexual behavior. The lower the social status of both participants, the more acceptable the behavior. Proscribed sexual relations between parties who have low social status, such as Negroes, criminals, or "low class," are more readily accepted than proscribed sexual acts between whites, conformers, or middle-class persons. The middle-class white woman, who is regarded as the custodian of American morals, is most strongly sanctioned for her behavior if it is defined as voluntary, but her

${ }^{12}$ In order that the sexual act leading to pregnancy be socially visible, the boy and girl would have to be observed in intercourse. Only the girl's sexual deviation is socially visible, however, in the pregnancy that ensues from the act. There is a special problem here anyway, since the father's status can never be proved in any absolute sense, while that of the mother is determinable.

${ }^{13}$ For a detailed discussion of just how incest interferes with status and role expectations in family socialization processes, see Talcotr Parsons \& Robert F. Bales, Famly Socialization and Interaction Process xox-03, and 305-06 (1950). 
involvement is most likely to be seen as that in which she is the victim of sexual aggression; it is intolerable to think of her as sexually aggressive.

The norms of American society permit women to use sex, particularly sex enticements, as a means to other ends-most specifically in her attempts to find a marriage partner. The male, however, is not permitted to use sex as a means; rather, he must seek it as an end in itself. The social status of adolescent boys in our society, especially within lower-status peer groups, rests in part on their sexual conquests. Among adolescent boys, in fact, it appears that gratification is less important in the sexual relationship with a woman than is the act of conquest itself, since conquest confers status within the peer group. Acts of sexual deviation that depart from the expectation that females must seek sexual activity as a means and males as an end in itself are more likely to arouse public indignation. It is more acceptable, therefore, for a low-status girl to advance her social position by coition with a higher-status male than it is for a low-status boy to initiate a sexual act toward a higher-status girl. For this reason, too, it is more acceptable for males socially to degrade themselves in the sexual act than it is for women to do so. Men are viewed as seeking sex as an end in itself, but women are allowed to seek it only as a means to other ends. For this reason, too, boys are allowed greater versatility in their choice of sexual partners (including animals) than are girls.

The degree to which the behavioral act departs from the model of heterosexual coition also is a factor in public reaction to deviating sexual behavior. Although mouth-genital fellation is a felony in most states, it is much less likely to be treated as a felony in heterosexual than in homosexual contract. Likewise, since infrahuman contacts depart most from the expectation, they have the lowest relative incidence of all major types of sexual activity and are most condemned.

Within American society, there are important subgroup differences in codes governing sexual conduct. The lower-status groups in American society, for example, generally sanction premarital sexual intercourse with the expectation that culmination in pregnancy prescribes marriage if the girl is "nice"-i,e., not sexually promiscuous. Similarly, this lower-status subgroup prefers (but does not prescribe) virginity in the female chosen as the marriage partner, but prescribes that the single male have regular outlets for heterosexual intercourse. ${ }^{14}$ There are subcultures, too, such as that of the beatniks, that prescribe any form of sexual act so long as it maximizes sexual gratification, ${ }^{15}$ or some delinquent ones that legitimize the role of prostitute with adult male fellators. ${ }^{16}$ Still other subgroups positively sanction celibacy and/or sexual continence, as, for example, men and women in religious orders.

There also are differences in structural opportunities for sexual deviation from

16 See Whyte, supra note 5 , at 29.

${ }^{15}$ Mailer, The White Negro, 4 Dissent 276 (1957).

${ }^{10}$ Albert J. Reiss, Jr. \& A. Lewis Rhodes, A Socio-Psychological Study of Adolescent ConFORMITY AND DEVIATION ch. 9 (r959). 
community to community and in the life situations of adolescents. ${ }^{17} \mathrm{~A}$ boy or girl residing in a lower-status, urban slum area has more opportunities to come into contact with certain forms of organized prostitution. The single-sex social structures and arrangements as found in school and college dormitories and training schools for boys and girls, with their increased sex segregation limiting heterosexual contact, lead to the availability of other forms of sex behavior. The typical state training school, for example, increases the exploitative homosexual contact between boys or girls of the same age and creates the role of the "punk" or "queer" among others. The differ-' ences in availability of contact with subgroups that hold norms positively sanctioning sexual behavior at variance with the legal norms of the larger society and the actual availability of opportunities to engage in deviating forms of sexual conduct are important factors, of course, in accounting for the patterned differences in sex behavior among adolescent subgroups in our society. In general, the lower-status adolescent boy living in a large metropolitan subcommunity that is homogeneously' lower-class is most likely to have experienced and positively to sanction all forms of sexual conduct. ${ }^{18}$

\section{II}

\section{The Relation of Adolescent Status to Soctal Sanctions for Sexual Deviation}

There is informal recognition among adults responsible for enforcing the sexual codes in our society that much sex deviation among single adolescents must be tolerated-that it is "normal" behavior and, therefore, it is a permissible, although not a preferred, form of behavior. This is particularly true of premarital heterosexual intercourse among adolescents. So long as an unwanted pregnancy does not occur and the partners are reasonably close to one another in age, the behavior seldom invites strong legal sanctions. Our culture, in fact, goes so far as to allow one to teach adolescents contraceptive behavior and the importance of recognizing and receiving treatment for venereal disease at the same time that it exhorts adolescents to shun premarital intercourse and legally prohibits it. The pragmatic in the culture requires at least that adolescents "be prepared" when they deviate (as we expect they will).

While heterosexual intercourse is permitted if it is a private act between an adolescent boy and girl, society clearly does not tolerate the behavior if it becomes public and thereby flouts the mores. Nowhere is this more apparent than in public reaction to the illegitimate child of the single adolescent girl. The boy is not treated as problematic in this case, but rather it is the girl who is the offender. It has been suggested that the reason for this is that pregnancy by its social visibility challenges the mores. The challenge must, perforce, be met with negative sanctions. ${ }^{19}$

While data on the incidence of premarital pregnancy are difficult to obtain, it seems clear that the lower-status girl, particularly of low-status ethnic minorities,

\footnotetext{
${ }^{17}$ See McKay, The Neighborhood and Child Conduct, 26 AnNaIs 32 (1949).

${ }^{18}$ Reiss \& RHodes, op. cit. supra note 16 , ch. 9.

${ }^{10}$ See Clark E. Vincent, Unwed Mothers (forthcoming).
} 
who also is of borderline intelligence and social skill is most likely to be made a legal offender for premarital pregnancy. From a social-problems perspective, of course, this type of girl poses the greatest risk for recidivism, so that it is not too surprising that she is selected for definition as a sex offender. But it must be remembered that she also is least able to defend herself before the courts or to seek extralegal assistance, given her life chances. Thus, a girl is more likely to be negatively sanctioned for premarital pregnancy if she is in the weakest power position to affect the legal sanctioning system and has least opportunity (and perhaps wish) to hide the social visibility of her deviation.

The failure to accord adolescents a distinct status position in American society, so that there are clear-cut expectations regarding their behavior, has implications for the degree to which punitive sanctions are employed in dealing with sexual deviation and the degree to which the adolescent is seen as morally responsible for the deviating act.

When the adolescent is defined as "not a child," the adolescent often is treated more punitively than an adult for the same act of sexual deviation. This is especially the case when the adolescent is viewed as a morally responsible agent who deliberately or voluntarily enters into an act of sexual deviation. An unmarried adolescent girl who is to bear a child often is sent to a delinquency institution for her act of sexual deviation, while an older woman who similarly bears an illegitimate child is not usually so sanctioned by the courts. (In both cases, of course, the babies are socially valued for their adoption status.) To choose another example, in New York State, adults are permitted to practice homosexual acts as private behavior, but juveniles are punished for private homosexual acts if it is known they have engaged in this form of sexual deviation. ${ }^{20}$

When the adolescent is defined as "not adult," society and its legal arm tend partially to absolve the adolescent from moral responsibility for the deviation and to protect the child from the full force of the sanctions, or altogether fail to sanction the behavior. This is usually the case when the adolescent is socially defined as the "victim" or "exploited party" in the sexual deviation. An adult who is viewed as exploiting an adolescent for sexual ends will be more severely punished for this than for the same act with an adult. The relationship between an adult male and an adolescent boy requires special discussion in this connection, since the social and legal definition of the relationship is one in which the adult male is defined as a homosexual who is exploiting the juvenile.

Recently, research has shown that the social definition of the sexual relationship between an adult male and an adolescent boy is in many cases erroneous. The homosexual act in a large proportion of cases occurs within a prostitute-client set of expectations, where the adolescent boy is the prostitute and the adult male is the client. From the standpoint of the lower-status delinquent boy who usually gets involved in this sexual relationship, the act is an instrumental one in which the boy

${ }^{20}$ N.Y. PENaL LAW $\S 690$. 
seeks adult males, particularly fellators, to minimize the risk in making money. A brief description of the way this behavior is organized in a number of metropolitan areas may serve as an illustration of what is involved in the relationship. ${ }^{21}$

Adolescent boys in delinquent gangs quite commonly seek out older males"queers"-to perform mouth-genital fellatio in exchange for money. These boys, however, have no conception of themselves as homosexual, although they view the fellator as a "gay" or "queer boy." The relationship, however, is quite clearly defined and prescribed as a part of the culture of career-oriented delinquents. There are a number of elements in this definition. Peer-hustling of "queers" is defined as an acceptable substitute for "legitimate" delinquent earnings (theft, for example) when one cannot afford to risk being caught. The "peer-queer" sexual transaction of mouth-genital fellation provides "easy money" for the delinquent boy at very low risk of being caught.

The delinquent boy often is inducted into this form of hustling by his older peers. He learns how contacts are to be made and where they are easily effected. Above all, he learns the norms and sanctions attached to the relationship. There are several such norms. He learns first of all that the sexual transaction with a "queer" must occur solely as a means of making money, that the relationship should be restricted to mouth-genital fellatio, that it must be affectively neutral, and that violence must not be used against the "queer" if he conforms to these expectations. For many career-oriented delinquent boys, then, hustling of "queers" is permitted. For other delinquent gangs, the practice becomes one of "queer-baiting," to roll the "queer" for his money, since he fears legal recourse to charge he has been robbed. In either case, the adolescent boy exploits adult males in the homosexual transaction, if exploitation is a meaningful term in this context.

The point to be made about legal sanctions in this context is that in many instances, the sexual transactions between adult males and adolescent boys arise precisely because both parties are outside the law. The laws of our society and the mores of the public define both delinquents and adults who engage in homosexual practices as deviators and restrict their opportunities to pursue their respective goals. Under these circumstances, it is not surprising to learn that the adult male who engages in homosexual acts and the delinquent pursue a mutually instrumental relationship.

In a fairly large number of cases involving an adult male and an adolescent boy in a sexual transaction, it is questionable whether the adult male seduces the adolescent boy. There are, of course, cases in which such seduction occurs. These cases of seduction, however, do not appear to involve large numbers of adolescent boys-certainly not to the point where the boys in the long run become involved in homosexual practices. Most of the delinquent boys who become involved in the

21 Investigation discloses it is quite common among career-oriented delinquents in such large metropolitan areas as Chicago, Los Angeles, New York, and Washington', D.C., and smaller ones such as Nashville, Tenn. It is observed in smaller cities. that attract large numbers of adult male homosexuals, such as the resort city of Hot Springs, Ark. 
"peer-queer" relationship described above do not continue the practices after adolescence. A small proportion of them undertake hustling careers, ${ }^{22}$ but most assume the typical lower-status adult male role of husband and father. The relationship never was defined by the boy as one in which he was in the social roles of either homosexual or prostitute.

The socioeconomic status of the adolescent is of some importance in the sanctions attached to sex violations. The higher the socioeconomic status of the adolescent's family in the community, the more likely the family is to afford legal counsel and, therefore, to require that the evidence clearly support the charges. In cases involving a sexual offense, it is particularly difficult to provide the necessary evidence to substantiate the charge. The court, therefore, is less likely to enter a finding of delinquency in cases where legal counsel are involved. It is unlikely that the boy or girl from a high-socioeconomic-status family who gets involved in a sex violation will be sent to a state-operated juvenile institution, since other and private means will be found to treat him or her-means of which the court will approve. For example, the lower-status pregnant girl who is single often is committed to a girl's institution as a sex delinquent. If a middle-status girl who is premaritally pregnant comes to the attention of the court at all (and she seldom does), the court will usually agree to her voluntary entry into a maternity home. Similarly, the middle-status family will seek the services of a psychiatrist or a clinician to treat its adolescent child involved in deviating sexual offenses such as exhibitionism or handling small children, and the court will adjudicate the case unofficially. The lower-status child with a similar offense often is committed to a public institution, where clinical treatment is given.

\section{III}

Some Problems in the Application of Legal Codes to Acts of Sexual

Deviation Involving Adolescents

Perhaps the most difficult problem in legally dealing with sex violators is that the incidence of sex offenses among adolescents far exceeds their adjudication. Although it is impossible to obtain precise estimates of the incidence or prevalence of deviation from the sex mores or legal codes defining sex violations, the rate for adolescents undoubtedly is very high. Kinsey estimates $:^{23}$

On a specific calculation of our data, it may be stated that at least 85 per cent of the younger male population could be convicted as sex offenders if law enforcement officials were as efficient as most people expect them to be.

A comparable estimate is not available for the younger females, although it is guessed below this figure. The simple fact is that it is quite difficult to detect persons in the act of committing a sex offense, given the essentially private circumstances under which they may occur and the circumstance that no other law is being

${ }^{22}$ See Ross, The Hustler in Chicago, I J. Student ReseArch 13 (1959).

${ }^{23}$ Kinsey Mate Report 224. 
violated. In addition, our social organization provides considerable support for evading detection for a sex offense, so that it is difficult to obtain sufficient evidence to enter a finding of sex delinquency. Most persons, including police officers, hesitate to risk the publicity associated with sex cases, including juvenile sex cases. While it would seem that the juvenile court procedures offer sufficient protection against publicity to persons offering testimony in such cases, the general public is unaware of this fact.

The result of this discrepancy between incidence and detection is that only the most socially visible offenses and offenders come to the attention of the court. Chance, therefore, may be the major factor in detection.

The interpretation of legal sex codes in our society is based on the assumption that juveniles are incapable of consenting to some kinds of sexual behavior or to a sex act that does not involve other adolescents. The adolescent in these cases is seen as exploited or seduced by others, usually older persons. Preceding discussion has emphasized that such an assumption is untenable, given the sex behavior of most adolescents in American society. Disregarding masturbation that may occur within a group setting, available evidence supports the view that (I) the majority of acts of sex deviation involving an adolescent occur only with other adolescents or at least persons relatively close to them in age; and (2) probably only a minority of sex contacts that adolescents have with older persons may be viewed as an act of exploitation or seduction on the part of the older person. A brief summary of some of the evidence in support of this proposition may serve to introduce the discussion that follows.

A majority of all boys and girls in the preadolescent years experience either homosexual and/or heterosexual sex play contrary to the mores. ${ }^{24}$ By the way of contrast, less than half as many boys and girls ever report they were approached by adults with sexual intent, and the large majority who report being approached report it was either verbal or exhibitionistic. When it is remembered that most such approaches to the preadolescent appear to come from adolescents rather than from older adult persons, it seems clear that the preadolescent sexual experience is largely confined to persons at their age level or that of an adolescent.

Heterosexual intercourse is primarily limited to partners within several years of one's own age. Intercourse with persons in organized prostitution does not involve a large proportion of boys or girls with a high frequency of contact. Among lower-status boys and girls, the group culture sanctions practices of heterosexual coition in a group setting. The older the adolescent boy or girl, the more likely, however, that the partner is an older teen-ager or person in the twenty-year age group. There is considerable evidence, however, that the major basis of induction into heterosexual intercourse is the peer society itself, and not through seduction by adults.

Homosexual practices often begin in the preadolescent period with other pre-

24 Id. at 168-74; Kinsey FeMrale Report ro8-io. 
adolescents. For lower-status boys in particular, the contact with adult males in sexual behavior is an instrumental one of "queer-baiting," described where the boy seeks out the "queer" to roll or assault him for his money or to steal his car, or enters into a prostitute-client sexual relationship with him because the sexual practice provides income with a minimum of risk. Induction into these homosexual practices, as noted, is defined and supported by the delinquent peer society, and its members often initiate younger members into the practices.

Thus, while some adolescents are seduced by older persons into acts of sexual deviation, the majority are not. Adolescents either mutually consent to the practices or they establish relationships with older persons in some form of organized prostitution in which the delinquent is the entrepreneur and purveyor of service.

It should be clear that these adolescent group determinants of deviant sex behavior may be more true for boys than for girls, and for low- than for middle- or high-status adolescents. It also seems to be the case that the low-I.Q. person is more likely to be victimized by older persons, although the evidence on this is not altogether clear, since low-I.Q. persons may be more socially visible in their acts of sexual deviation.

If this thesis is correct-and to some extent it must be regarded as a tentative formulation-then the question arises: Why is it commonly thought that most adolescents are victims of sexual aggression. There are a number of ways to answer this question. Not all of them are given in this discussion.

There is, first of all, the obvious explanation that the public and the courts come into contact only with those adolescents who are frightened or traumatized by the sexual activity. Only those adolescents who perceive of themselves as victims will bring their cases to the attention of the public or to the juvenile authorities. Adolescents who voluntarily enter into sexual relations with adults-and who, therefore, do not see themselves as exploited-seldom come to the attention of the public or legal authorities. A public and legal image, therefore, is created that the victimized person is the most common. Research evidence leads to the conclusion that this is not the case.

A second explanation lies in the social definitions we are taught regarding when we are to perceive of ourselves as victims in sexual behavior. We are taught to see ourselves as victims when the person is a stranger and we do not voluntarily enter into the act. Involvement with an older person who is a stranger, therefore, is most likely to lead an adolescent to define the situation as one in which he was a victim. Research shows, however, that in sexual relationships involving an older person and an adolescent or child, more often than not the older person who victimizes the child is a close friend or a relative rather than a stranger. Cases involving a close friend or relative are more likely to be dealt with through informal rather than legal means, however, since it is less easy to express indignation against these persons than it is to express it against a stranger. Courts, therefore, tend to get only 
those cases where the public definitions lead one to define oneself as a victim and where the adult, therefore, was a stranger.

A third kind of explanation is that the ambiguity in the sexual mores vis-à-vis sexual practices, coupled with the ambivalence most persons have toward sexual aggression, leads to a shared definition that an adolescent involved in any sexual behavior with other persons is a victim of the other person. Regard, for example, the fact that many middle-status parents do not wish to define their children as sexually mature, since this may force them as parents to cope with the sexual maturity of the child on a reality level. So long as the child is regarded as sexually immature, any discovery that their adolescent child is involved in acts of sexual deviation, then, is more likely to be explained on grounds that the child was a victim, since the adolescent is not seen as voluntarily seeking such activity for goal satisfaction. Certainly, parents are relatively unaware that their son, on the average, is more sexually active than he ever will be in his life or that their daughter is about as sexually active as she ever will be, as measured by the average frequency of orgasm in total sexual outlet. $^{25}$ Among lower-status parents, there probably is greater acceptance of many of the practices, so that there is less ambivalence toward their child's deviation. The lower-status family actually may support the deviation in more subtle ways, even though it may exact conformity at the verbal level.

Public indignation, as already noted, is more likely to reach its peak when acts of sexual deviation involve older persons and adolescents, particularly if they are publicly defined as homosexual or "unnatural" acts. The agencies of law enforcement, adjudication, and treatment also single out these kinds of acts for special consideration. From the police, who are most likely to arrest such offenders, to the courts and the newspapers or gossips, who are most likely to report them, these acts come to be conceived as the most common forms of sex acts involving preadolescents or adolescents when they are not. Let it be clear that no position is taken that public indignation should not be expressed against such acts. The point expressed here is that out of public indignation emerges a conception of reality that these are the major forms of sexual deviation involving adolescents when this is not the case.

To extend the point further, it appears, on reflection, that there is far more heterosexual intercourse among adolescents than any premarital pregnancy figures would disclose, that our social arrangements are likely to foster homosexual relations among persons of the same age and social origins, and that opportunities for sex deviation are related to one's social position in a community and the availability of organizational structures in it that support sex deviation. These social facts, of course, are the major determinants of the process of induction into deviating behavior, whether it is sexual or some other form of normative deviation. They account, too, for the structural variation in deviating behavior.

The moral concern about adolescents being involved in heterosexual coition cannot be adequately dealt with by arrest and adjudication for a number of reasons.

${ }^{25}$ Kinsey Male Report 219-20; Kinsey Female Report 518-29. 
There is, first of all, the fact that it is extremely difficult to detect and apprehend juveniles who engage in premarital coitus. Kinsey and his associates report that their records show fewer than six of each roo,00o copulations are discovered in progress. Furthermore, their records show no instance of legal adjudication arising from any of these discoveries. While some persons are charged with the offenses of premarital coitus, in no instance did the charge arise from actual discovery. Rather, conviction was based on other kinds of evidence and testimony. ${ }^{2 B}$ This very difficulty in detection means that those who are detected must necessarily be the objects of selective discrimination, since they represent only a very small proportion of the total population engaging in the behavior.

The police, who are primarily charged with law enforcement, do not usually think of heterosexual intercourse as an offense. This may be so for a number of reasons, including the fact that the sex histories of policemen usually show similar violations in their youth. The point might be generalized, however. Since a substantial proportion of all males and almost nine of every ten lower-status males experience heterosexual intercourse as adolescents, and most of them are not ever discovered or adjudicated as offenders, it seems reasonable to conclude that most males inevitably are ambivalent toward arresting an unmarried adolescent for heterosexual coition, given the punitive action that may follow arrest.

Since premarital coitus is a moral concern to the families of adolescents and since the status reputation of an adolescent girl depends upon her maintaining her social status as a virgin (she may long since have actually lost her virginity), the adolescent peer society makes it difficult to detect and sanction deviation from the norms. Many violations of the sexual conduct norms, in fact, are maintained as a private concern to protect the individual from both the judgment of the peer society and that of the adult society.

Though tangible evidence is generally lacking, Kinsey and others report there is considerable variation in the way judges handle cases of premarital intercourse, depending upon their social origins. They suggest that the closer the social origin of a judge to lower-status origin, the more likely he is to be lenient in adjudication of cases involving premarital coitus. ${ }^{27}$

There likewise is considerable evidence that the norms of both adolescents and adults do not support either therapeutic or punitive action for acts of premarital coition. It is not the behavioral act of heterosexual intercourse that is to be avoided as much as its consequences. The consequences of contracting a venereal disease, of pregnancy, or of the status of being promiscuous are to be avoided in the view of most adolescents.

Given these fundamental problems in detecting and adjudicating cases of premarital coition among adolescents, together with the problematic aspects of what

\footnotetext{
${ }^{28}$ Kinsey Fenale Report 326.

${ }^{2 \tau} I d$. at 325; Paul W. Tappan, Juvenile Delinguency 264 (1949); Lane, lllogical Variations in Sentences of Felons Committed to Massachtetsets State Prison, 32 J. CRIM. L. \& CRIM. I7I (I94I).
} 
to do with violators, it seems doubtful that rational legal enforcement of norms is possible. This is not, of course, to deny that heterosexual coition is a problem of moral concern to be dealt with by other institutional forms of organization in the society.

Evidence shows that the homosexual behavior of lower-status adolescent boysparticularly that of career-oriented delinquents-occurs either as an organized form of prostitution or in some exploitative form of "queer-baiting." From the standpoint of the processes of law enforcement and adjudication of offenses, the adult male homosexual who is involved with adolescents should not in most cases be thought of as making the adolescent a victim of his homosexuality. Rather, the adolescent boy in many instances should be viewed as a self-styled delinquent proprietor who purveys an illegal service at a price fixed by fair-trade agreements. The relationship between the adult male homosexual and the lower-status boy is fundamentally rooted in a set of social definitions that the adolescent and the homosexual share as deviators. The relationship is supported by a delinquent subculture and peer society.

There is little doubt, of course, that such behavior affronts public morality and, therefore, is a problem for law enforcement and adjudication. To define it as a criminal violation for the adult homosexual and an exploitation of the juvenile, however, misstates the problem for legal adjudication. Other faulty ideas also interfere with a rational approach to the problem. A punitive approach to the adult male homosexual's offense does not deal with the problem of his homosexuality. To view the delinquent as a homosexual offender would ignore the fact that it occurs within an organized set of understandings commonly referred to as prostitution. It also would ignore the fact that the relationship arises as part of patterned delinquent activity. Making money from "queers" is part of. a versatile pattern of careeroriented delinquency. Any legal attempt to deal with the problem under special laws for sex offenders will fail to recognize that fundamentally the act does not represent a sex offense to these boys, but rather an easy way to make money with a minimum of risk. To deal with the problem in moral terms requires a concerted approach to the problem of the prevention of delinquency on the one hand and the problem of adult male homosexuality on the other.

The discussion in this article has in large part proceeded on the assumption that the incidence of sexual deviation in an adolescent population is far greater than statistics on arrest or adjudication show. It has not dealt directly with the question of what would happen if the arrest rate were increased? How would cases be adjudicated? This problem is akin to that which arises for all types of deviation covered by juvenile court statutes. What would happen if we substantially increased the arrest rate for petty thievery, for example? These questions arise, however: Would there be reasons for not increasing the arrest rate? And would there be reasons for handling the sex offender cases differently?

It has already been observed that the problem of deviation from heterosexual pre- 
marital intercourse and masturbation norms is probably more realistically a matter for institutional organizations dealing with private morality, unless, of course, the norms governing heterosexual intercourse among adults are violated, such as those for prostitution or public exhibition. Other forms of sexual deviation undoubtedly will continue to be proscribed as institutionalized legal norms, but it is technically difficult to increase the arrest rate for these forms of behavior, given their organized aspects.

The question of what should be done with sex offenders clearly is a difficult one to answer. In attempting to provide an answer to this question, one must bear in mind that the type of sexual deviation influences not only public response, but adjudication and treatment. Should the single girl who is pregnant be placed with the girl who practices homosexuality or the venereally-infected prostitute? Should the unwed mother and the father of the child be dealt with as a unit? Should the careeroriented delinquent who has a sexual liaison with "queers" be treated as a sex offender as well? And, so on. From a social and psychological point of view, much more needs to be known about both the causes of types of sexual deviation and the ways to deal with offenders of each kind before the advisability of increasing the arrest rate or of changing the laws governing the incarceration and treatment of sexual offenders can be seriously considered.

The delinquent boy or girl who is adjudged a recidivisit often is sent to an institution for delinquents. There are several different kinds of such institutions, the most common of which is a training school. Such institutions house boys who are guilty of almost any kind of offense, including sex offenses. A basic characteristic of these institutions is that the population is highly segregated on age, sex, and even socioeconomic status lines. Thus, they are generally for adolescent girls or boys from lower-status families. Although some institutions may segregate for therapeutic purposes or programs, these criteria of social differentiation remain.

From a sociological point of view, juvenile institutional populations are the most experienced in sex behavior of any subgroup in the population. Furthermore, as already noted, at least among boys, adolescence is the age for the highest total sexual outlet-i.e., at this age, one finds the highest average frequency of sex acts to orgasm. To institutionalize such an adolescent subgroup is to exacerbate the problem of sex deviation. The institution itself becomes a basis for all forms of homosexual and infrahuman sex offenses. Under these circumstances, boys will exploit boys and girls exploit girls.

In delinquent boys' institutions, the most common form of sexual exploitation is that of "punking." A "punk" often is forced to provide a variety of homosexual outlets to the other adolescent boys (although as his status of a "punk" becomes fixed in the status structure of the institution, he may engage in sexual practices in exchange for money or other resources). He may be a fellator, adopt the passive roles in pederasty, bestiality, or "slick-laying," as well as engage in a variety of other homosexual acts. While such acts receive strong negative sanctions from the insti- 
tutional personnel and some boys refuse to participate in them, a large number of institutionalized boys come to accept them as alternative forms of sexual gratification. In the words of one such boy, "you ain't got much choice, and after you've been here awhile anythin' looks like it'd do."

There seems little doubt that the typical training school for boys or girls fosters highly deviating sex practices within the institution. Yet, except for the "punk," there is little evidence that the homosexual behavior persists when the boy is released from the institution nor that it persists into adulthood, unless the boy or girl also is institutionalized in a closed institution for a criminal population.

There does not seem to be any necessary reason for sex segregation in the institutional treatment of most delinquent boys and girls. The experimental programs. begun several decades ago by August Aichhorn and considerably modified by Bruno Bettelheim at the Sonia Shankman Orthogenic School of the University of Chicago ${ }^{28}$ and Fritz Redl in the Pioneer House experiments in Detroit ${ }^{29}$ provide considerable. evidence that delinquent boys and girls-even those who are seriously disturbed emotionally-can be treated in the same open institution in a community without. fostering the deviating practices so commonly found in training schools. Parenthetically, it must be emphasized, however, that these institutions are not primarily custodial, but treatment institutions organized on the principle of controlling themilieu of the child within the institution and the community, while gradually reintegrating the child into the community. Still, it must be recognized that social science as yet is unable to demonstrate that such institutions will work for delinquent boys and girls who do not present problems of emotional disturbance, but for whom deviant activity, including sex offenses, is primarily the result of socialization in an environment that positively sanctions the deviation-the behavior is normative within the group; it confers status. Despite this reservation, the single-sex institution of the custodial form is no answer to the problem of the boy or girl who is a sex offender.

\section{Epilogue}

The problem of adjudicating cases involving sex offenses is a very difficult one. The statutes defining juvenile delinquency are sufficiently broad in scope so that. any violation of the sex mores of American society can lead to adjudication of the offender as a delinquent. There is no question then of the kind: Are our juvenile laws sufficiently comprehensive so as to cover all violations of the sex mores as acts of delinquency? The questions which seem more appropriate are: Does there seem to be any way of avoiding the arbitrary application of the statutes to delinquent offenders? And are the criminal statutes regarding the relationship of adults with adolescents in sex offenses sufficiently congruent with the social definition of these acts among the participants? There is a further question: Will the public permit the-

${ }^{28}$ See Bruno Bettelheim, Truants From Life (1955); Love Is Not Enough (1950).

${ }^{20}$ See Fritz Redl \& David Wineman, Controls From Within (1952); Children Who Hate. (195I). 
courts to deal with offenders involved in sex offenses with adolescents or between adolescents themselves in other than punitive terms? Will it accept an approach to the problem that is oriented toward dealing with the causal sequence in the behavior, or will public indignation demand punishment of violators as criminal offenders?

This article has offered some evidence and argument to suggest that private heterosexual behavior involving consent among participants, one or both of whom are adolescents, regardless of their status, cannot be adequately controlled nor can justice be met by legal action. Because it is a moral problem, it is not one for which legal action will be effective. On the other hand, when the heterosexual behavior occurs within such institutional forms as prostitution, or there is clear exploitation or absence of consent on the part of the adolescent, the behavior clearly necessitates legal intervention. How the adolescent is to be dealt with in these situations, however, should be approached in terms of the modern concepts of prevention and treatment.

All other sex behavior, except the private one of masturbation, clearly offends public morality in our society, and the community at large does not appear ready to accept any change in the legal codes regarding these offenses. Despite this limitation, juvenile officials will need to recognize that there is considerable variation in the social organization of these kinds of behavior, so that an approach to the problem where the individual is treated as a sex offender may fail to affect its organized aspects.

Often one hears that the sex mores are changing or that more young people deviate now than hithertofore. Such statements may be correct, but they are essentially without proof. They, therefore, cannot form the basis for any change in our legal institutions. The data now available are for a cross-section of some population within the past few decades. They do not tell us how things have changed. To the degree that there have been changes in the mores, however, the sexual act no longer is regarded as deviating (or at least not as serious), and any attempt to buttress the older mores by legal institutional means will make it a relatively ineffective means of control in American society.

Under some concepts of treatment for delinquent adolescents, the adolescent may even escape moral responsibility for the delinquent conduct. The atomistic view of delinquent behavior and treatment that focuses on treating an individual delinquent and a delinquent as an individual is one such conception of treatment. One consequence of this conception is that adjudication and treatment of offenders often fails to regard the delinquent behavior in the context of the moral integration of American society. The norms of adolescent groups, the status of adolescents in the larger social structure, and their behavior as a consequence of these conditions need to become a focal point of concern if the moral integration of the society is to be preserved. The focus on individual violators to the exclusion of the matrix within 
which their violation is embedded can only lead to a further destruction of the social and moral integration of the society.

The discussion in this article was offered to show that the failure to accord adolescents a distinct status within the social structure of American society, together with the failure to institutionalize norms governing their behavior as adolescents weakens the moral integration of the total society. It would seem to follow that efforts to define a distinct status position where the expectations are that an adolescent behave as a morally responsible individual within the larger society should alter some of the conditions giving rise to the problems discussed. Attention needs to be focused particularly on what are the culturally-approved goals toward which adolescents are expected to move, what are the means that they may appropriately use to reach them, and what rights and responsibilities are they to have in the total society. 